\title{
COVID-19: spreading possibilities of human-animal-human and preventive measures
}

\author{
Prasannavenkatesan Theerthagiri and Vamsidhar Yendapalli \\ Department of Computer Science and Engineering, GITAM School of Technology, \\ GITAM University Bengaluru, Bengaluru, India
}

\begin{abstract}
Purpose - This paper reviews the possibilities of coronavirus disease 2019 (COVID-19) spreading from infected humans to pet animals and from pet animals to other animals and humans.

Design/methodology/approach - A systematic literature review and meta-analysis were performed on research articles from November 2019 to August 2020. This study explored urgently needed research issues on COVID-19 infection spreading across animals and humans and vice versa.

Findings - Essential and much needed precautionary measures and necessary preventive steps to protect pet animals from infection were highlighted.

Originality/value - Essential investigation and experiment results were highlighted. The necessary measure to prevent the spread of infection among and across species and people was analyzed.
\end{abstract}

Keywords COVID-19, Animal-human, Infection, Preventive measures, Pets

Paper type Mini review

\section{Introduction}

The start of 2020 is also the beginning of the rapid spread of coronavirus $(\mathrm{CoV})$ in humans . The world is struck with an epidemic of coronavirus disease 2019 (COVID-19). First, it has emerged at the end of 2019 in Wuhan, China. The rate of infection and death is very high. Such that the World Health Organization (WHO) announced the COVID-19 disease as a pandemic. The COVID-19 is the variant of the Middle East Respiratory Syndrome (MERS) and Severe Acute Respiratory Syndrome (SARS) viruses, which also caused the epidemics a few years ago. The virological and genetic studies on these viruses are suggested and confirmed that the bats are the sources for these families of different viruses [1].

In order to develop the therapies and vaccines, a suitable animal model is much needed. Several kinds of research are underway on determining the intermediate animal host of SARS-CoV-2, which caused infection among humans. The animal mammals such as bats and pangolins have the worth for extensive research on whether they act as the intermediate animal host for the SARS-CoV-2 virus to humans [2].

\section{Methodology}

This paper reviews the meta-analysis on possibilities of COVID-19 spreading from animal to human (transmission across various species) based on existing research studies. The systematic literature review and meta-analysis have been done on research articles from

(C) Prasannavenkatesan Theerthagiri and Vamsidhar Yendapalli. Published in Journal of Health Research. Published by Emerald Publishing Limited. This article is published under the Creative Commons Attribution (CC BY 4.0) licence. Anyone may reproduce, distribute, translate and create derivative works of this article (for both commercial and non-commercial purposes), subject to full attribution to the original publication and authors. The full terms of this licence may be seen at http:// creativecommons.org/licences/by/4.0/legalcode

Declaration of competing interest: The authors declare that they have no known competing financial interests or personal relationships that could have appeared to influence the work reported in this paper.

\section{Spreading possibilities of COVID-19}

Received 9 September 2020 Revised 23 September 2020 29 September 2020

Accepted 7 October 2020 
JHR 35,4

\section{6}

Figure 1.

Method of metaanalysis
November, 2019 to August, 2020. Figure 1 depicts the method of meta-analysis and overview of the literature review. The literature is collected from ScienceDirect, Google scholar, PubMed/Medline and other resources. The research works are identified by searching the keyword (372). The duplicate articles/research papers, draft works and grey literature are excluded (93). These articles are further filtered (41) according to the theme of this paper. From 41 research articles/papers, 20 works are referenced in this paper.

\section{COVID-19 across companion-animals}

As the COVID-19 originated from animals, it leads to the discussion on possibilities of transmission diseases with the contact of pets. During January, 2020, China's National Health Commission had raised the issue of spreading of the COVID-19 among companion animals from their owners or through the contact with the outbreak. As the COVID-19 epidemic virus spreads between the mammals, the commission suggested few necessary precautions for the pet owners and the pets. In the month March, 2020, the WHO stated the pets are safe from the infection of COVID-19 [3].

Later in the same month, the pets also got the infection from the outbreak. Then the WHO admitted that the pet could be infected and suggested that with the lack of evidence that the possibility of spreading by animals and wild animals to humans is rare and minimal. The WHO also does not have a clear idea of whether the animals (pet/wild) can be sources of the COVID-19 virus that can spread to humans and other animals. After that, the first infection in animals (tiger) by transmission from human (zookeeper) is confirmed in the Bronx zoological garden [3-5].

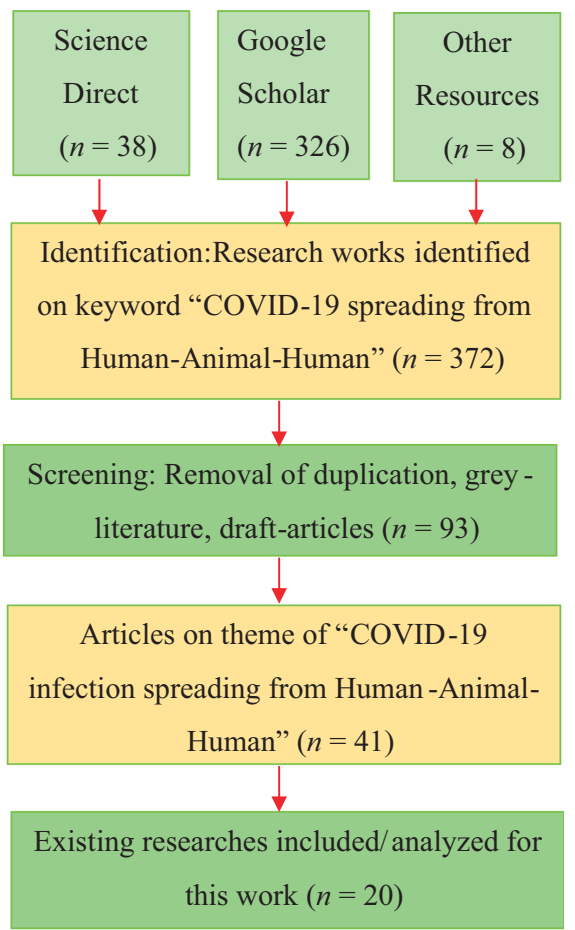


Further, the Ministry of Health in Singapore reported the possibilities of spreading COVID-19 from animals to humans and humans to animals. Also, they considered that the pets are not a serious reservoir for the transmission of the virus [1, 2, 6]. Figure 2 illustrates the possible ways of COVID-19 infection transmission among the animal-human-animal-human cycle.

Shreen et al. [7] had reported that the consumption of CoV-infected animals as the food might be the cause of the transmission of the virus from animal to human. Further, it was recommended that the utilizing and consumption of live animals and birds as the food by humans should be banned.
Spreading possibilities of COVID-19

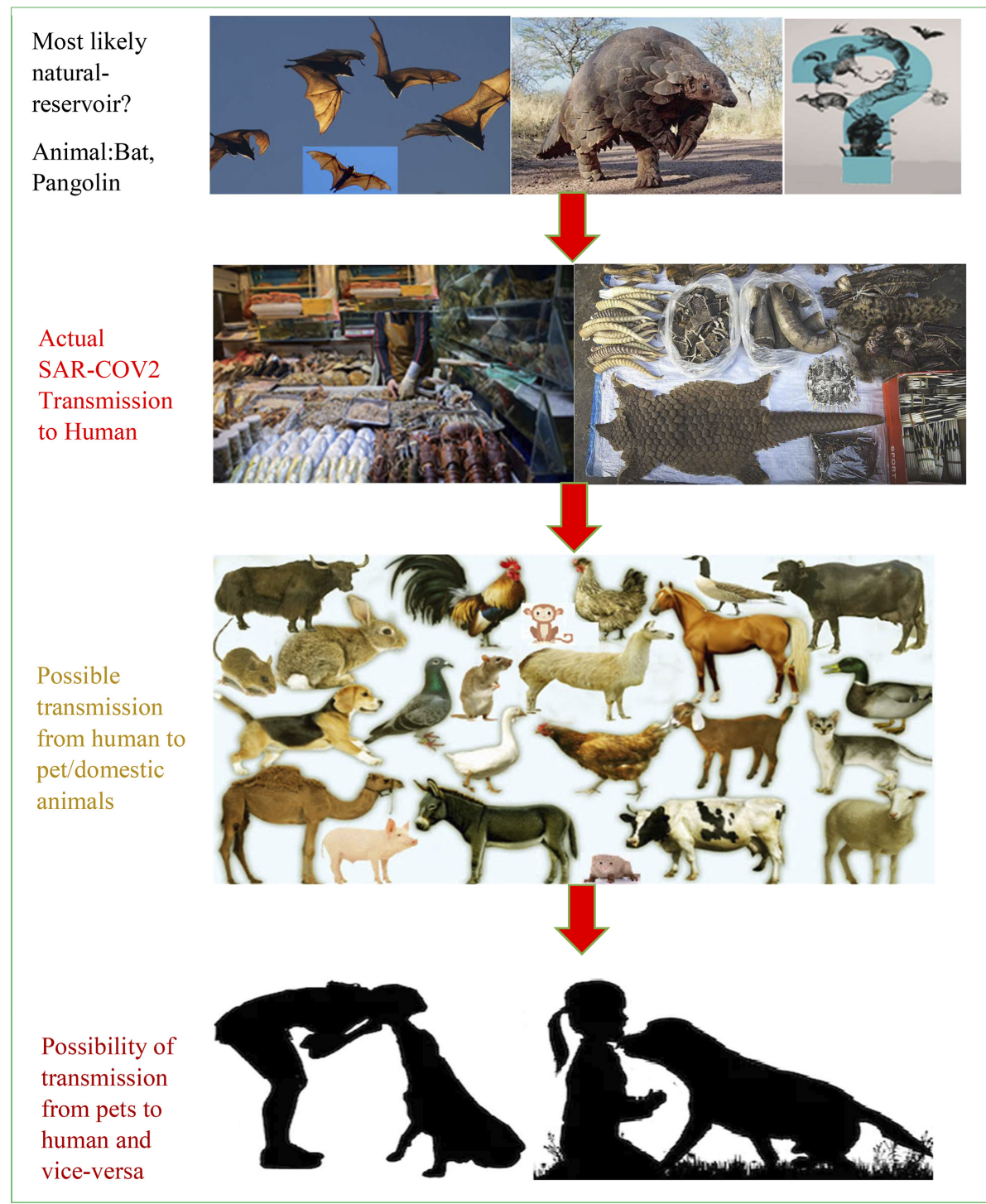

Figure 2. COVID-19 transmission 
JHR

35,4

\section{8}

Typically, it was suggested that the CoVs could affect the various mammal species and birds including companion animals such as dogs/cats/monkeys, cows/horses/whales, etc. Also, the nature of the CoVs is mutations, which means it can transmit the infection among other animals, including humans, and make them zoonotic pathogens [8]. Further, it was suggested that CoVs might spread among diverse animal species. However, the intermediate animal host of the SARS-CoV-2 virus is still under investigation [9].

\section{Results on infection from companion animal to human}

In medical history, animal contact is the common high-risk factor for transmitting infection from animals to humans. Sahin et al. [10] reported that the family of CoVs is common in bats, cattle, camels and cats. It is also stated that from these animals, the CoVs can spread to infect humans. Even in the recent years, the family of these viruses (MERS/SARS) has infected humans and caused epidemics [11]. Further, palm cats and dromedary camels caused the outbreaks with $\mathrm{CoV}$ viruses SARS/MARS $[6,12,13]$. The genetic and virological studies confirm that bats are a natural reservoir for the family of $\mathrm{CoV}$ viruses such that SARS/MARS is found in bats before it spreads to humans [10].

In July 2020, it was confirmed that the COVID-19 virus spread from minks to humans $[14,15]$. Extensive understanding is required on the COVID-19 virus's gene expression in different animal species and its possible transmission to other species [1]. Appendix 1 gives the list of animals infected by the SAR-CoV-2 virus (which causes COVID-19 in humans) in the United States, according to the World Organization for Animal Health (OIE) [16].

\section{Discussion on preventive measures from COVID-19}

Since the COVID-19 infection is dispersed among the human population worldwide, we should follow precautions to avoid the transmission of infection from humans to other companion animals [14]. Few companion animals were infected from close contact with their owners [17]. Pet and zoo animals such as cats, dogs, minks, tigers, etc. tested positive for COVID-19 infection with respiratory and other clinical signs, where humans were the primary source of the reservoir for the infection $[9,14,18,19]$. Further, nowadays, we have seen a few implications such as the transmission of $\mathrm{CoV}$ infection from animals back to humans (as human-animal-human) [17].

\section{Research concerns, challenges and preventive measures}

Even the current pandemic is triggered by the human to another human by transmission (notdriven by animals), we should immediately need to concern with few necessary precautions.

(1) An extensive study and further experiments are required to understand the susceptibility of COVID-19 infection transmission from animals to humans and its infection dynamics across the mammals. It is essential to identify the susceptible animal species for the COVID-19 infection and transmission across animals and humans.

(2) A meta-analysis is required on the prevalence of genetic characteristics of pet animals and other animals infected by the SAR-CoV-2 virus. Most importantly, there is a need to develop the vaccines or therapies; the vaccines can be developed based on the genetic structure of intermediate host animal, which spread the infection to humans. Such that significant research should be concentrated to determine the intermediate host animal as well.

(3) A few studies suggested the pigs, mice and poultry (chickens, ducks, etc.) are not susceptible to the COVID-19 infection and transmission [17, 20], and a few other reports suggested that they are susceptible. Moreover, later in July 2020, the farmed 
mink transmitted the infection back to humans. Therefore, extensive studies and experiments are crucial in order to continue the consumption of these animals as food for humans.

(4) The results from other experiments and investigations suggest the companion cats, ferrets and dogs are more susceptible to getting infected by humans. Therefore, extensive study and analysis are required to ascertain the possibility of these reverting the infection to humans or the same animal species. Further study is required on the possibilities of companion animals transferring the infection to humans.

(5) Recently, the ferrets were studied and investigated in order to evaluate the vaccines or therapeutics for the COVID-19 viruses. This raises the question of the other animals that can be assessed for the development of vaccines or therapeutics. Also, the success ratio of testing vaccines on animals to humans is questionable.

(6) Some investigations suggested dogs are less susceptible to the infection than cats and ferrets. It is also necessary to evaluate the possibilities of transmission of infection back to the human.

(7) It was suggested that bats might be the natural reservoir for the $\mathrm{CoV}$ transmission to humans. Further, it was identified that the $\mathrm{CoV}$-infected bats could transfer the infection to the other bats. Thus, more research into bats is required.

(8) Similarly, increased research into the spread of the virus among different species of animals would help reduce the spread of the virus among other species.

(9) There are ongoing studies and investigations on non-human primates such as different monkey species, including grivets, rhesus-macaques, marmosets, and cynomolgus-macaques, that are infected in the laboratory environment. This necessitates the investigations on transmission of infection from humans to monkeys.

(10) Since the monkeys are roaming across human habitations for their foods and other needs, it also necessary to analyze the humans getting infected from the monkeys in order to prevent such transmissions in the future.

(11) It is also suggested that dogs can get infected from humans and can spread COVID-19 to the other animals. Further, the possibilities of transmission back to humans are ambiguous. Even though the possibility of infection is rare, it requires the precautionary measures to prevent the infection.

(12) Most studies are ambiguous, partly because investigations and experiments are performed on a small, significantly small number of animals. Moreover, there is a massive ambiguity on whether the infected animals can spread the virus infection back to humans.

(13) Therefore, to understand the transmission nature of infection among animals, larger-scale investigations are urgently needed to safeguard the animals and people from COVID-19.

(14) In this ambiguous scenario, to ensure pets are not infected by people or vice versa, or pets do not infect other animals, we should follow a few precautious measures. 
JHR

35,4

(15) Until a vaccine is successfully tested or we have explicit knowledge of infection spreading across the animal species, we should treat our companion animals with the following cares.

- We should avoid the pets from interacting with other animals and humans outside of our household.

- We need to keep our pets indoors to prevent outside infection.

- We should maintain social distancing while walking among dogs or cats from other outside animals, even with the people.

- Do not let pets out in public places with other dogs, for example, with street dogs or other animals.

- Do not let our pets out in the people crowded places [21].

\section{Conclusions}

As the susceptibility of the animal to human transmission of the COVID-19 virus is ambiguous, we need to follow a few precautious measures. In this paper, various possibilities of animal infection among different species are studied. Regarding the human-animalhuman infection scenario, many questions may arise. Few of them are as follows: what is the reliability of the poultry or livestock animals that will not get infected by SARS-CoV-2? What is the reliability of the results with few experiments, which says animal to human transmission of infection is rare? With few results, how can one say the pigs, duck and hens cannot be the virus reservoirs for the infection in humans? What are the testing methods available for the identification of infection in poultry or other animal species?.

\section{References}

1. McNamara T, Richt JA, Glickman L. A critical needs assessment for research in companion animals and livestock following the pandemic of COVID-19 in humans. Vector Borne Zoonotic Dis. 2020; 20(6): 393-5. doi: 10.1089/vbz.2020.2650.

2. Enserink M. Coronavirus rips through Dutch mink farms, triggering culls. Science. 2020; 368(6496): 1169. doi: 10.1126/science.368.6496.1169.

3. Jurgiel J, Filipiak KJ, Szarpak , Jaguszewski M, Smereka J, Dzieciątkowski T. Do pets protect their owners in the COVID-19 era? Med Hypotheses. 2020; 142: 109831. doi: 10.1016/j.mehy.2020. 109831.

4. Safoora. Virus panic: owners throw away pets from highrise buildings. 2020. [updated 2020 February 1; cited 2020 September]. Available from: https://www.siasat.com/virus-panic-ownersthrow-away-pets-highrise-buildings-1812619/.

5. Wan Y, Shang J, Graham R, Baric RS, Li F. Receptor recognition by the novel coronavirus from Wuhan: an analysis based on decade-long structural studies of SARS coronavirus. J Virol. 2020; 94(7): e00127-20. doi: 10.1128/jvi.00127-20.

6. Shi J, Wen Z, Zhong G, Yang H, Wang C, Huang B, et al. Susceptibility of ferrets, cats, dogs, and other domesticated animals to SARS-coronavirus 2. Science. 2020; 368(6494): 1016-20. doi: 10.1126/ science.abb7015.

7. Shereen MA, Khan S, Kazmi A, Bashir N, Siddique R. COVID-19 infection: origin, transmission, and characteristics of human coronaviruses. J Adv Res. 2020; 24: 91-8. doi: 10.1016/j.jare.2020. 03.005 .

8. Seah I, Agrawal R. Can the coronavirus disease 2019 (COVID-19) affect the eyes? A review of coronaviruses and ocular implications in humans and animals. Ocul Immunol Inflamm. 2020; 28(3): 391-5. doi: 10.1080/09273948.2020.1738501. 
9. Li X, Zai J, Zhao Q, Nie Q, Li Y, Foley BT, et al. Evolutionary history, potential intermediate animal host, and cross-species analyses of SARS-CoV-2. J Med Virol. 2020; 92(6): 602-11. doi: 10.1002/ jmv.25731.

10. Sahin AR, Erdogan A, Agaoglu PM, Dineri Y, Cakirci AY, Senel ME, et al. Novel coronavirus (COVID-19) outbreak: a review of the current literature. Eurasian J Med Oncol. 2020; 4(1): 1-7. doi: 10.14744/ejmo.2020.12220.

11. Sia SF, Yan LM, Chin AWH, Fung K, Choy KT, Wong AYL, et al. Pathogenesis and transmission of SARS-CoV-2 in golden hamsters. Nature. 2020; 583(7818): 834-8. doi: 10.1038/s41586-020-2342-5.

12. Mahmud AH. 'Theoretical possibility' that COVID-19 can spread from animals to humans, but pets not a serious vector of transmission: MOH. 2020. [updated 2020 March 10; cited 2020 September]. Available from: https://www.channelnewsasia.com/news/singapore/coronavirus-petsspread-possibility-singapore-moh-covid-19-12508030.

13. Zhou Y. WHO says pets are generally safe from being infected with coronavirus. 2020. [updated 2020 March 12; cited 2020 September]. Available from: https://qz.com/1816853/your-dogs-and-catscannot-spread-the-coronavirus/.

14. Theerthagiri P. Probable forecasting of epidemic COVID-19 in using COCUDE model for the state of Tamilnadu, India. Research Square. 2020. preprint. doi: 10.21203/rs.3.rs-41348/v1.

15. Chen Y, Liu Q, Guo D. Emerging coronaviruses: genome structure, replication, and pathogenesis. J Med Virol. 2020; 92(4): 418-23. doi: 10.1002/jmv.25681.

16. U.S. Department of Agriculture, Animal and Plant Health Inspection Service. Cases of SARS-CoV-2 in animals in the United States. 2020. [cited 2020 September]. Available from: https:/www.aphis.usda. gov/aphis/ourfocus/animalhealth/sa_one_health/sars-cov-2-animals-us.

17. World Organisation for Animal Health. Questions and answers on COVID-19. 2020. [cited 2020 September]. Available from: https://www.oie.int/scientific-expertise/specific-information-andrecommendations/questions-and-answers-on-2019novel-coronavirus/.

18. Theerthagiri P, Jacob IJ, Ruby AU, Vamsidhar Y. An investigation of machine learning algorithms on COVID-19 dataset. Research Square. 2020. preprint. doi: 10.21203/rs.3.rs-70985/v1.

19. Sowman HR, Cave NJ, Dunowska M. A survey of canine respiratory pathogens in New Zealand dogs. N Z Vet J. 2018; 66(5): 236-42. doi: 10.1080/00480169.2018.1490214.

20. Centers for Disease Control and Prevention [CDC]. COVID-19 and animals. 2020. [cited 2020 September]. Available from: https://www.cdc.gov/coronavirus/2019-ncov/daily-life-coping/ animals.html.

21. U.S. Food and Drug Administration [FDA]. Helpful questions and answers about coronavirus (COVID-19) and your pets. 2020. [cited 2020 September]. Available from: https://www.fda.gov/ consumers/consumer-updates/helpful-questions-and-answers-about-coronavirus-covid-19-andyour-pets. 
35,4

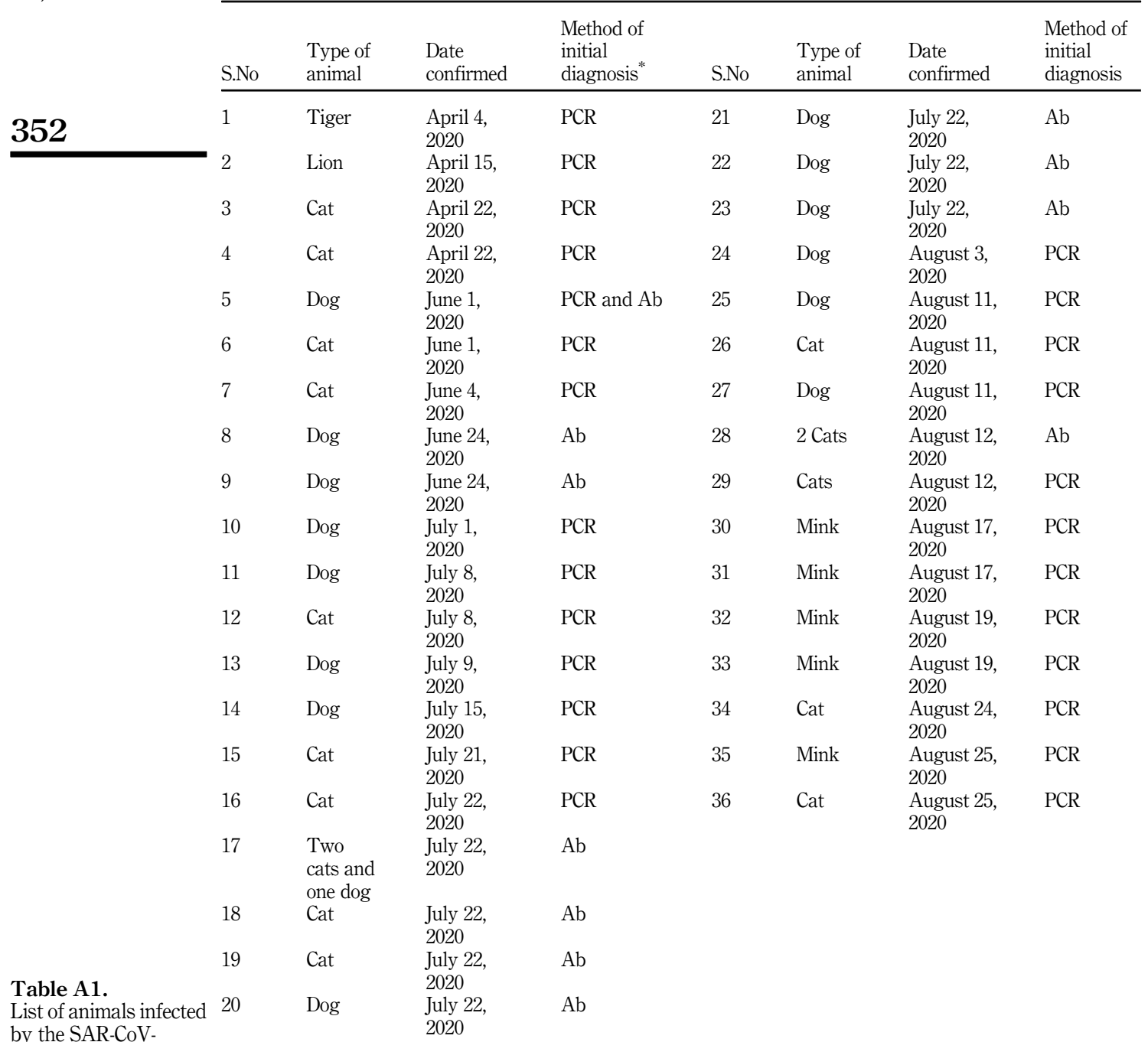

Note(s): "PCR: real-time reverse transcription polymerase chain reaction; Ab: virus neutralizing antibody

\section{Corresponding author}

Prasannavenkatesan Theerthagiri can be contacted at: prasannait91@gmail.com

For instructions on how to order reprints of this article, please visit our website:

www.emeraldgrouppublishing.com/licensing/reprints.htm

Or contact us for further details: permissions@emeraldinsight.com 